\title{
Variety of Sporulation Phenotypes Resulting from Mutations in a Single Regulatory Locus, spoIIA, in Bacillus subtilis
}

\author{
By J. ERRINGTON AND J. MANDELSTAM* \\ Microbiology Unit, Department of Biochemistry, University of Oxford, Oxford OXI 3QU, U.K.
}

(Received 31 December 1982; revised 14 February 1983)

Closely linked mutations in either of the two putative genes of the sporulation locus spoIIA can affect, in quite diverse ways, spore incidence, the production of alkaline phosphatase and DNAase, and the stability of the cells in sporulation medium. It is concluded that the locus has a regulatory function affecting the activation or induction of at least two, and possibly more, sporulation-associated operons.

\section{INTRODUCTION}

Alkaline phosphatase and DNAase are two extracellular enzymes whose production is associated with stage II of sporulation in Bacillus subtilis. Mutants blocked early in stage II produce neither of the enzymes; those blocked later produce both (Waites et al., 1970; Piggot \& Coote, 1976; Akrigg \& Mandelstam, 1978; Young \& Mandelstam, 1979). It is not known whether they play a direct role in sporulation or whether they belong to a category of secondary events (Coote \& Mandelstam, 1973). The question could be settled by isolating mutants in which the structural genes for the enzymes are damaged, but, in spite of considerable effort, no such mutants have been found (Grant, 1974; Porter \& Mandelstam, 1982).

The specific associations of alkaline phosphatase and DNAase with stage II could be explained in one of two ways. First, the genes for the enzymes might be included in operons that lie in the main sequence whose successive expression is necessary for the formation of the spore. Alternatively, they might lie on operons unconnected with the main sequence. These might be switched on either by the same regulator molecule that activates an operon in the main sequence or by some other molecule such as an intermediary metabolite generated by some biochemical change, e.g. enzymic action of a protein coded for in the main sequence.

This paper describes the phenotypic consequences of a number of closely linked mutations in the spoIIA locus. Earlier work had shown that mutations in this locus result not only in asporogeny or oligosporogeny but also in failure to produce alkaline phosphatase (Coote, 1972 $a$; Piggot, 1973). It was subsequently shown that there is also a failure to produce extracellular DNAase (Akrigg \& Mandelstam, 1978). None of the later sporulation events, e.g. production of glucose dehydrogenase or dipicolinic acid, occurred in these mutants. These results all suggest that spoIIA is a 'main-stream' locus. More recently, Yudkin \& Turley (1981) showed that mutations in one part of the locus could be partly suppressed by another mutation elsewhere in the same locus and that this altered not only the degree of oligosporogeny but the rate at which sporulation occurred. Furthermore, Liu et al. (1982) cloned part of the spoIIA locus on a plasmid and demonstrated that this plasmid would complement mutations that had been shown by Yudkin \& Turley (1981) to lie at one end of the locus, whereas mutations lying at the other end could not be complemented. It thus appears that the spoIIA locus contains at least two separate genes.

The experiments described in this paper show that closely linked mutations within either of the putative genes can produce quite different effects on alkaline phosphatase, DNAase and sporulation. They also affect in different ways the stability of the cells in sporulation medium. 
Table 1. Bacillus subtilis strains

Strain

spo ${ }^{+}$strains

168

MB68

MB75

MY2016

spo mutants

1

37

42

50

63

69

\section{Strain Relevant genotype}

SG16

1.1

37.1

42.1

50.2

63.6

69.4

560

561

562

563

564

565

1.3

37.2

42.2

50.3

63.6

69.6

560.1

561.1

562.1

563.1

564.1

565.1
$\operatorname{trpC2}$

lys-1 phe-12 rif-2 tal-1

lys-1 metC3 tal-1

hisH2 lys-1 rif sul ${ }^{\mathrm{R}}$

trpC2 spoIIAI

trpC2 spoIIA37

trpC2 spoIIA42

trpC2 spoIIASO

trpC2 spoIIA63

trpC2 spoIIA69

hisH2 $\mathrm{spo}^{+}$

hisH2 spoIIAI

hisH2 spoIIA37

hisH2 spoIIA42

hisH2 spoIIA50

hisH2 spoIIA63

hisH2 spoIIA69

hisH2 spo560

hisH2 spo56I

hisH2 spo562

hisH2 spo563

hisH2 spo564

his $H 2$ spo565

lys-1 spoIIAI

lys-1 spoIIA37

lys-1 spoIIA42

lys-1 spoIIA50

lys-1 spoIIA63

lys-1 spoIIA69

lys-1 spo560

lys-1 spo561

lys-1 spo562

lys-1 spo563

lys-1 spo564

lys-1 spo565
Previous designation and reference

Yudkin \& Turley (1980)

El (Piggot, 1973)

NG1.82 (Piggot, 1973)

NG6.13 (Piggot, 1973)

NG1 1.2 (Piggot, 1973)

NG16.2 (Piggot, 1973)

NG18.6 (Piggot, 1973)

Constructed strains

\section{Construction}

MY2016 transformed to Lys $^{+}$using DNA from strain 168

MY2016 transformed to $\mathrm{Lys}^{+}$using the appropriate spo donor above, and spo transformants isolated

Mutants isolated by transformation of MY2016 to Lys ${ }^{+}$using mutagenized DNA from strain 168 (see Results)

MB75 transformed to $\mathrm{Met}^{+}$using the appropriate hisH2 spo donor above, and $\mathrm{Spo}^{-}$congressants isolated

The results can be most simply explained by assuming that the locus codes for a regulator protein that plays an essential part in the main sporulation pathway and that the same regulator also controls the production of the two extracellular enzymes and a factor (a lytic enzyme?) affecting the stability of the cells.

\section{METHODS}

Organisms. The bacterial strains used are shown in Table 1.

Media. Hydrolysed casein growth medium and sporulation medium were as described by Sterlini \& Mandelstam (1969). Penassay broth was from Oxoid. Solid media were Oxoid nutrient agar and lactate/glutamate minimal agar (Piggot, 1973). Where appropriate the latter was supplemented with L-amino acids at a final concentration of $200 \mu \mathrm{g} \mathrm{ml}^{-1}$.

Growth and sporulation. Cultures were grown at $37^{\circ} \mathrm{C}$ with shaking except where otherwise stated. Culture density was measured turbidimetrically at $600 \mathrm{~nm}$ with a Unicam SP600 spectrophotometer and readings were converted to $\mathrm{mg}$ dry wt bacteria $\mathrm{ml}^{-1}$. Sporulation was achieved using the resuspension technique of Sterlini \& Mandelstam (1969). Times (h) after resuspension in sporulation medium are denoted $t_{1}, t_{2}, t_{3}$, etc.

Transformation. DNA was extracted from donor cultures as described by Ward \& Zahler (1973), except where otherwise indicated, and was used to transform recipient cultures made competent by the method of Anagnostopoulos \& Spizizen (1961). Prototrophic recombinants were selected on lactate/glutamate minimal agar 
supplemented with the appropriate amino acids. Spo ${ }^{+}$transformants were selected on Schaeffer's agar (Schaeffer et al., 1965) by treatment with chloroform vapour as described by Hoch (1971).

Directed mutagenesis and mutant isolation. Mutations in the spoIIA locus were obtained by making use of its linkage (about $30 \%$ ) to lys -1 by transformation (Yudkin \& Turley, 1981). Heavily mutagenized DNA was prepared from strain $168\left(\mathrm{Spo}^{+}\right)$as follows. A culture in penassay broth $(200 \mathrm{ml})$ was grown to a density of about $0 \cdot 15 \mathrm{mg}$ dry wt $\mathrm{ml}^{-1}$. The cells were harvested by centrifugation and resuspended in $10 \mathrm{ml}$ sporulation medium containing $N$ methyl- $N^{\prime}$-nitro- $N$-nitrosoguanidine $\left(100 \mu \mathrm{g} \mathrm{ml}^{-1}\right)$. After $40 \mathrm{~min}$ incubation with shaking the cells were harvested by centrifugation, washed twice in sporulation medium, and resuspended in $200 \mathrm{ml}$ penassay broth. After further incubation ( $1 \mathrm{~h}$, with shaking) DNA was extracted using the method of Marmur (1961). The final yield of DNA was estimated to be about $36 \mu \mathrm{g}$ by measurement of absorption at $260 \mathrm{~nm}$ on a Unicam SP800 spectrophotometer.

This DNA was used at a final concentration of $0 \cdot 1 \mu \mathrm{g} \mathrm{ml}^{-1}$ to transform MY2016 to Lys ${ }^{+}$as described above. After incubation for 3 to $4 \mathrm{~d}$ it was possible to identify sporulation mutants on the basis of their failure to produce the characteristic brown pigment associated with sporulation. Potential mutants were purified by repeatedly streaking them on $\mathrm{Lys}^{+}$selective medium. Microscopic examination of nutrient agar cultures after $3 \mathrm{~d}$ allowed those mutants that were highly oligosporogenous to be identified and discarded. In the remaining strains the spo mutations were tested for linkage to $l y s-l$ by transformation of strain MB68 to Lys ${ }^{+}$. Those that showed less than $10 \%$ linkage were also discarded.

Mapping. Three-factor transformation crosses were used for two purposes: firstly, to show that the new mutations lay on the same side of $l y s-l$ and in or near the spoIIA locus; secondly, to order different mutations in the spoIIA locus with respect to lys- 1 . The basis was as follows. Suppose that spo- $X$ and spo- $Y$ (below) represent two different mutations, one of which, spo- $X$, is known to lie in the spoIIA locus, while the other, spo- $Y$, shows similar transformation linkage to $l y s-1$ but may lie on either side of it. There are three possible positions for $s p o-Y$ :

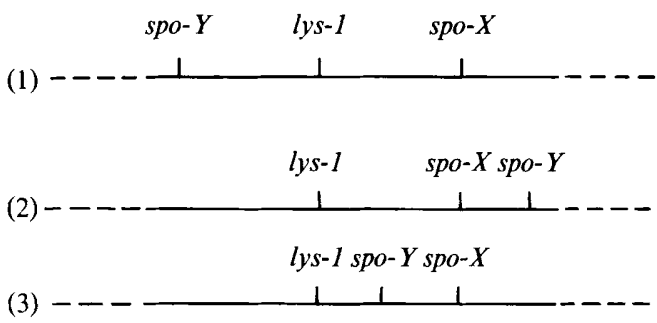

These three possible orientations can be distinguished using reciprocal three-factor crosses as follows. Cross A : Recipient, lys-1 spo- $X$; donor, Lys ${ }^{+}$spo- $Y$. Cross B: Recipient, lys-1 spo- $Y$; donor, Lys ${ }^{+}$spo- $X$. In both crosses, $\mathrm{Lys}^{+}$transformants can be selected and scored as $\mathrm{Spo}^{+}$or $\mathrm{Spo}^{-}$on the basis of colony pigmentation. If the order (1) above is correct then both crosses should give about $30 \% \mathrm{Spo}^{+}$transformants among the Lys ${ }^{+}$transformants because spoIIA is $30 \%$ linked to lys. However, if either (2) or (3) represents the correct order, then the proportions of $\mathrm{Spo}^{+}$transformants in both crosses would be greatly reduced. If both $s p o-X$ and spo- $Y$ lie on the same side of lys- 1 , their relative positions can be inferred by comparing the ratios of $\mathrm{Spo}^{+} / \mathrm{Lys}^{+}$among the transformants in the reciprocal crosses. In one cross, two crossovers would be required to give $\mathrm{Spo}^{+}$transformants, whereas in the other, four crossovers would be necessary.

The map distance between two mutations can be estimated by dividing the frequency of $\mathrm{Spo}^{+}$transformants by the frequency of $\mathrm{Spo}^{+}$transformants using DNA from an isogenic $\mathrm{Spo}^{+}$donor (strain SG16). The resulting value is the recombination index (RI) (Lacks \& Hotchkiss, 1960) as described by Coote (1972b).

$$
\mathrm{RI}=\frac{\text { Frequency of } \mathrm{Spo}^{+} \text {among Lys }{ }^{+} \text {transformants (spo DNA) }}{\text { Frequency of } \mathrm{Spo}^{+} \text {among } \mathrm{Lys}^{+} \text {transformants (spo DNA) }}
$$

Isolation of plasmid DNA. Escherichia coli strain SL3030 (Liu et al., 1982), carrying the plasmid pHM2, was kindly provided by P. J. Piggot. Plasmid DNA was purified from this strain by the method of Guerry et al. (1973) after amplification using $300 \mu \mathrm{g}$ spectinomycin $\mathrm{ml}^{-1}$ (Klein et al., 1980).

DNAase detection agar. This was prepared as described by Porter \& Mandelstam (1982). DNAase detection plates were inoculated from overnight nutrient agar cultures. Production of DNAase was indicated by a halo of decolorization of the medium around the inoculum. Results were recorded after 2 to $3 \mathrm{~d}$ at $37^{\circ} \mathrm{C}$.

Enzyme assays. Alkaline phosphatase was assayed using a variation of the method of Glenn \& Mandelstam (1971). Culture $(1.5 \mathrm{ml})$ was mixed with $1 \mathrm{ml}$ of $p$-nitrophenol phosphate (Sigma) $\left(1 \mathrm{mg} \mathrm{ml}^{-1}\right.$ in $1 \mathrm{M}-\mathrm{Tris} / \mathrm{HCl}$ $\mathrm{pH} 8.0)$ and incubated at $30^{\circ} \mathrm{C}$. When the colour $\left(A_{410}\right)$ was judged to have reached a value of about $0 \cdot 2$, the reaction was stopped by adding $1 \mathrm{ml} 2 \mathrm{M}-\mathrm{NaOH}$ and the time was noted. The concentration of $p$-nitrophenol 
phosphate in the supernatant was determined by measuring the $A_{410}$. One unit of enzyme is defined as the amount that hydrolyses one nmol p-nitrophenol phosphate in $1 \mathrm{~min}$ at $30^{\circ} \mathrm{C}$. Manganese-dependent DNAase was assayed as described by Akrigg (1978). One unit of DNAase is defined as the amount that produces $1 \mathrm{nmol}$ of acid-soluble nucleotides in $20 \mathrm{~min}$ at $37^{\circ} \mathrm{C}$. Glucose dehydrogenase was assayed as described by Sadoff (1966). One unit is defined as the amount of enzyme that reduces $1 \mathrm{nmol} \mathrm{NAD} \min ^{-1}$ at $37^{\circ} \mathrm{C}$. Dipicolinic acid content was measured as described by Janssen et al. (1958).

Incidence of heat-resistant spores. Sporulating culture $\left(0.1 \mathrm{ml}\right.$ taken at $\left.t_{9}\right)$ was added to $0.9 \mathrm{ml}$ sporulation medium, then heated at $85^{\circ} \mathrm{C}$ for $15 \mathrm{~min}$. Samples $(0 \cdot 1 \mathrm{ml})$ of the treated culture, or a suitable dilution of it, were plated on nutrient agar and colonies were counted after $24 \mathrm{~h}$ at $37^{\circ} \mathrm{C}$. Values are given as the number of heatresistant c.f.u. $\mathrm{ml}^{-1}$ in the original culture.

\section{RESULTS}

\section{Directed mutagenesis of the lys-1 region}

Twenty-nine sporulation mutants were obtained that showed more than $10 \%$ linkage to lys- 1 by transformation. Microscopic examination of nutrient agar cultures after $2 \mathrm{~d}$ suggested that 12 were blocked before stage III. The mutations in all 12 showed about $30 \%$ linkage to lys- 1 , which is similar to that of other mutations in the spoIIA locus (Yudkin \& Turley, 1981).

\section{Production of alkaline phosphatase and DNAase in spoIIA mutants}

Previous investigations (Waites et al., 1970; Piggot, 1973; Akrigg \& Mandelstam, 1978) showed that spoIIA mutants do not produce alkaline phosphatase ( $\mathrm{Pho}^{-}$phenotype) or DNAase ( $\mathrm{Nuc}^{-}$phenotype) during sporulation. However, preliminary screening of the 12 possible spoIIA mutants using DNAase detection agar showed that five of them produced DNAase $\left(\mathrm{Nuc}^{+}\right)$ whereas the remainder did not $\left(\mathrm{Nuc}^{-}\right)$. These $\mathrm{Nuc}^{+}$mutants, 560, 561, 562, 563 and 564, and one of the $\mathrm{Nuc}^{-}$strains, 565, were then tested quantitatively for DNAase production during sporulation. Alkaline phosphatase was also measured since production of this enzyme is usually correlated with production of DNAase in sporulation mutants (Akrigg \& Mandelstam, 1978).

All five $\mathrm{Nuc}^{+}$mutants produced both DNAase and alkaline phosphatase: the values at $t_{5}$ were roughly half of those found for the wild-type. Strain 565 and all of the previously characterized spoIIA mutants produced insignificant amounts $(<5 \%)$ of these enzymes (Table 2). Although the former mutants did not produce the full amounts of alkaline phosphatase and DNAase, they were clearly 'positive' in the qualitative sense and will therefore be referred to as possessing the $\mathrm{Pho}^{+} \mathrm{Nuc}^{+}$phenotype. The time-course of production of both enzymes was similar in all $\mathrm{Pho}^{+} \mathrm{Nuc}^{+}$mutants to that of the wild-type (see Figs 3 and 4). Generally, alkaline phosphatase activity began to appear after $1.5 \mathrm{~h}$ in sporulation medium and DNAase about $1 \mathrm{~h}$ later.

These mutants had all been obtained by introducing mutagenized DNA into the same recipient strain and should therefore have been isogenic. It was nevertheless possible that some other mutations producing partial suppression of the $\mathrm{Spo}^{-} \mathrm{Pho}^{-} \mathrm{Nuc}^{-}$phenotype had been introduced inadvertently into these strains. For this reason the mutations spo-561 and spo-562 were transferred by congression with $\mathrm{Met}^{+}$into strain MB75 (met lys). The transformants were checked and found to have the same sporulation phenotypes as their parents.

\section{Other phenotypic properties of the mutants}

None of the new sporulation mutants produced glucose dehydrogenase or dipicolinic acid (later sporulation marker events) during sporulation (data not shown). Although some of the mutants were oligosporogenous (Table 2), this trait was not correlated with the production of alkaline phosphatase and DNAase since at least one $\mathrm{Pho}^{-} \mathrm{Nuc}^{-}$mutant (42.1) was also oligosporogenous.

The $\mathrm{Pho}^{+} \mathrm{Nuc}^{+}$mutants differed from the $\mathrm{Pho}^{-} \mathrm{Nuc}^{-}$mutants in one further characteristic. It was observed that cultures of $\mathrm{Pho}^{+} \mathrm{Nuc}^{+}$mutants tended to lyse in sporulation medium, whereas cultures of $\mathrm{Pho}^{-} \mathrm{Nuc}^{-}$strains did not (see Fig. 1 for a typical result). For the first $4 \mathrm{~h}$ of incubation no difference was observed between strains $560\left(\mathrm{Pho}^{+} \mathrm{Nuc}^{+}\right), 1.1\left(\mathrm{Pho}^{-} \mathrm{Nuc}^{-}\right)$and 


\section{Table 2. Phenotypic properties of spoIIA mutants}

Cultures $(15 \mathrm{ml})$ were induced to sporulate as described in Methods. Samples were taken at intervals for measurement of sporulation marker events.

\begin{tabular}{|c|c|c|c|}
\hline Strain & $\begin{array}{l}\text { Alkaline } \\
\text { phosphatase } \\
\text { activity at } t_{5} \\
\text { (units } \mathrm{ml}^{-1} \text { ) }\end{array}$ & $\begin{array}{c}\text { DNAase activity } \\
\text { at } t_{5} \\
\text { (units } \mathrm{ml}^{-1} \text { ) }\end{array}$ & $\begin{array}{c}\text { Heat resistance } \\
\text { at } t_{9} \\
\text { (c.f.u. } \mathrm{ml}^{-1} \text { ) }\end{array}$ \\
\hline $\mathrm{SG} 19\left(\mathrm{Spo}^{+}\right)$ & 93 & 1100 & $\mathrm{Spo}^{+}\left(2.4 \times 10^{8}\right)$ \\
\hline 560 & 41 & 700 & High Osp $\left(2.2 \times 10^{5}\right)$ \\
\hline 561 & 36 & 560 & Low Osp $\left(1.8 \times 10^{2}\right)$ \\
\hline 562 & 34 & 370 & Low Osp $\left(1.0 \times 10^{2}\right)$ \\
\hline 563 & 37 & 580 & Low Osp $\left(3.0 \times 10^{2}\right)$ \\
\hline 564 & 38 & 640 & Low Osp $\left(1.5 \times 10^{2}\right)$ \\
\hline 565 & $3 \cdot 8$ & 0 & $\mathrm{Spo}^{-}\left(<5 \times 10^{1}\right)$ \\
\hline 1.1 & 3.5 & $3 \cdot 0$ & $\mathrm{Spo}^{-}\left(<5 \times 10^{1}\right)$ \\
\hline 37.1 & 2.8 & $2 \cdot 3$ & $\mathrm{Spo}^{-}\left(<5 \times 10^{1}\right)$ \\
\hline 42.1 & $3 \cdot 3$ & $4 \cdot 5$ & High Osp $\left(1.2 \times 10^{5}\right)$ \\
\hline 50.2 & $1 \cdot 0$ & 0 & $\mathrm{Spo}^{-}\left(<5 \times 10^{1}\right)$ \\
\hline 63.6 & $1 \cdot 3$ & 0 & $\mathrm{Spo}^{-}\left(<5 \times 10^{1}\right)$ \\
\hline 69.4 & $4 \cdot 0$ & 3.9 & $\mathrm{Spo}^{-}\left(<5 \times 10^{1}\right)$ \\
\hline
\end{tabular}

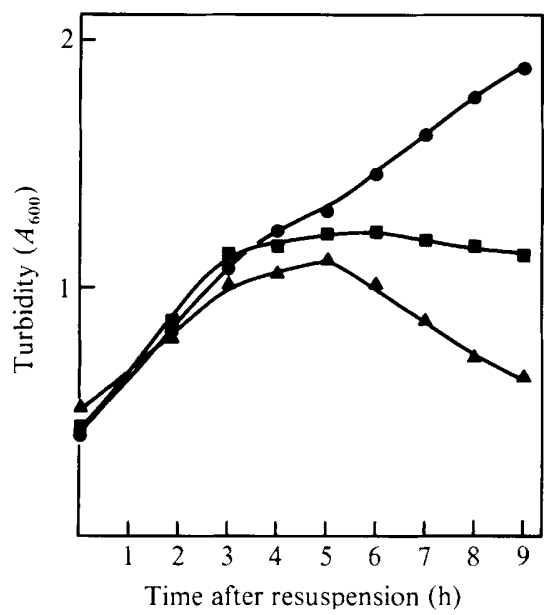

Fig. 1. Growth during sporulation. SG16 $\left(\mathrm{Pho}^{+} \mathrm{Nuc}^{+} \mathrm{Spo}^{+}\right)(\mathbf{O}), 42.1\left(\mathrm{Pho}^{-} \mathrm{Nuc}^{-} \mathrm{Osp}\right)(\square)$ and 560 $\left(\mathrm{Pho}^{+} \mathrm{Nuc}^{+} \mathrm{Osp}\right)(\boldsymbol{\Delta})$ were induced to sporulate as described in Methods. At intervals the turbidity $\left(A_{600}\right)$ of each culture was measured.

the wild-type. After $t_{4}$ or $t_{5}$, however, the turbidity of strain 560 began to decline whereas that of strain 1.1 remained relatively constant. The wild-type culture reached a plateau and then showed a renewed increase in turbidity between $t_{5}$ and $t_{9}$, probably as a result of the development of refractile spores. In similar experiments all $\mathrm{Pho}^{+} \mathrm{Nuc}^{+}$mutants behaved like strain 560, and $\mathrm{Pho}^{-} \mathrm{Nuc}^{-}$mutants behaved like strain 1.1 (data not shown).

\section{Mapping of spoIIA mutations}

The phenotypic properties of the $\mathrm{Pho}^{+} \mathrm{Nuc}^{+}$mutants suggested that their mutations lay in a hitherto unrecognized locus distinct from spoIIA. Accordingly, three-factor crosses were carried out to determine the positions of the new mutations with respect to $l y s-1$ and the previously characterized spoIIA mutations (Table 3). Recombination indices (Table 4) were calculated (see Methods) and the distances shown on the map (Fig. 2) are given in terms of these. These data showed that the new mutations were interspersed throughout the previously mapped portion of the spoIIA locus (Yudkin \& Turley, 1981). Liu et al. (1982) showed that there are at least two 
Table 3. Three-factor crosses

Reciprocal three-factor crosses were performed as described in Methods. Lys ${ }^{+}$transformants were selected and examined for their Spo phenotype

\begin{tabular}{|c|c|c|c|c|}
\hline $\begin{array}{l}\text { spo mutation } \\
\text { in recipient }\end{array}$ & $\begin{array}{l}\text { spo mutation } \\
\text { in donor }\end{array}$ & $\begin{array}{l}\text { Proportion of } \\
\text { Spo }^{+} \text {among Lys } \\
\text { transformants }\end{array}$ & $\begin{array}{l}\text { Percentage } \\
\text { of } \mathrm{Spo}^{+}\end{array}$ & Probable map order* \\
\hline spoIIAI & spo-560 & $11 / 1350$ & $0 \cdot 81$ & \multirow[t]{2}{*}{ lys-1 . . spoIIA $1 \ldots$ spo-560 } \\
\hline spo-560 & spoIIAI & $7 / 2640$ & $0 \cdot 27$ & \\
\hline $\begin{array}{l}\text { spoIIAI } \\
\text { spo-56I }\end{array}$ & spo-561 & $\begin{array}{l}14 / 1990 \\
5 / 1560\end{array}$ & $0 \cdot 70$ & \multirow[t]{2}{*}{ lys-I . . spoIIAI . . spo-56I } \\
\hline $\begin{array}{l}\text { spo-56I } \\
\text { spoIIAI }\end{array}$ & $\begin{array}{l}\text { spollaI } \\
\text { spo-562 }\end{array}$ & $\begin{array}{l}5 / 1560 \\
62 / 1120\end{array}$ & 0.32 & \\
\hline spo-562 & spoIIAI & $\begin{array}{l}02 / 1120 \\
47 / 3530\end{array}$ & $\begin{array}{l}5 \cdot 3 \\
1 \cdot 3\end{array}$ & lys-I . . spoIIA I . . spo-562 \\
\hline spoIIA37 & spo-564 & $15 / 2150$ & $0 \cdot 70^{7}$ & \multirow{2}{*}{$1 y s-1 \ldots$ spo-564 . . spoIIA37† } \\
\hline spo-564 & spoIIA37 & $10 / 1350$ & $0 \cdot 74$ & \\
\hline spoIIA42 & spo-562 & $10 / 2660$ & $0 \cdot 38$ & \multirow{2}{*}{ lys-1 $\ldots$ spoIIA442 $\ldots$ spo-562 } \\
\hline spo-562 & spoIIA42 & $4 / 1640$ & $0 \cdot 24$ & \\
\hline spoIIA42 & spo-565 & $28 / 6770$ & $0 \cdot 41$ & \multirow{2}{*}{ lys-1 . . spoIIA442 . . spo-565 } \\
\hline spo-565 & spoIIA42 & $9 / 5190$ & $0 \cdot 17$ & \\
\hline spoIIA69 & spo-562 & $5 / 6200$ & $0 \cdot 081$ & \multirow{2}{*}{ lys-1 . spo-562 . . spoIIA69 } \\
\hline spo-562 & spoIIA69 & $13 / 6190$ & $0 \cdot 21$ & \\
\hline spoIIA69 & spo-565 & $6 / 6160$ & 0.097 & \multirow{2}{*}{ lys-1 . . spo-565 . . spolla69 } \\
\hline spo-565 & spoIIA69 & $10 / 3390$ & $0 \cdot 28$ & \\
\hline spo-560 & spo-561 & $12 / 3000$ & $0 \cdot 40$ & \multirow{2}{*}{$l y s-1 \ldots$. . spo-561 . . spo-560 } \\
\hline spo-561 & spo-560 & $54 / 7030$ & 0.77 & \\
\hline spo-560 & spo-562 & $285 / 5660$ & $5 \cdot 0$ & \multirow{2}{*}{ lys-1 . . spo-560 . . spo-562 } \\
\hline spo-562 & spo-560 & $110 / 6050$ & $1 \cdot 8$ & \\
\hline spo-560 & spo-563 & $184 / 6910$ & $2 \cdot 7$ & \multirow{2}{*}{ 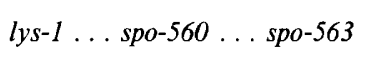 } \\
\hline spo-563 & spo-560 & $21 / 1840$ & $1 \cdot 1$ & \\
\hline spo-560 & spo-564 & $109 / 3420$ & $3 \cdot 2$ & \multirow{2}{*}{ lys- $1 \ldots$ spo-560 . . spo-564 } \\
\hline spo-564 & $s p o-560$ & $12 / 1220$ & $1 \cdot 0$ & \\
\hline spo-562 & spo-564 & $187 / 8400$ & $2 \cdot 2$ & \multirow{2}{*}{$l y s-1 \ldots$ spo-564 . . spo-562 } \\
\hline spo-564 & spo-562 & $45 / 1050$ & $4 \cdot 3$ & \\
\hline spo-562 & spo-565 & $0 / 18000$ & 0 & \multirow{4}{*}{ 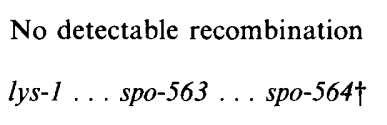 } \\
\hline spo-565 & spo-562 & $0 / 20000$ & 0 & \\
\hline spo-563 & spo-564 & $14 / 1750$ & $0 \cdot 80$ & \\
\hline spo-564 & spo-563 & $37 / 6060$ & $0.61\}$ & \\
\hline
\end{tabular}

* This was determined as described in Methods.

$\dagger$ The order given is not determinable from the three-factor cross, but is consistent with data from two-factor crosses.

Table 4. Recombination indices for pairs of mutations in the spoIIA locus

Recombination indices were determined (see Methods) to obtain a measure of the distance between spo mutations.

$\begin{array}{ll}\text { spo mutation } & \text { spo mutation } \\ \text { in recipient } & \text { in donor } \\ \text { spoIIAI } & \text { spo-560 } \\ \text { spoIIAI } & \text { spo-561 } \\ \text { spoIIAI } & \text { spo-562 } \\ \text { spoIIAI } & \text { spo-565 } \\ \text { spoIIA42 } & \text { spo-562 } \\ \text { spoIIA42 } & \text { spo-565 } \\ \text { spo-560 } & \text { spoIIA69 } \\ \text { spo-560 } & \text { spo-562 } \\ \text { spo-560 } & \text { spo-563 } \\ \text { spo-560 } & \text { spo-564 } \\ \text { spo-561 } & \text { spo-560 } \\ \text { spo-562 } & \text { spoIIA69 } \\ \text { spo-563 } & \text { spo-564 } \\ \text { spo-564 } & \text { spoIIA37 } \\ \text { spo-564 } & \text { spo-562 } \\ \text { spo-564 } & \text { spo-565 } \\ \text { spo-565 } & \text { spoIIA69 }\end{array}$

Percentage of $\mathrm{Spo}^{+}$colonies

$\begin{array}{lcc}(a) \text { spo DNA } & (b) s p o^{+} \mathrm{DNA} & \begin{array}{c}\mathrm{RI} \\ {[(b) /(a)]}\end{array} \\ 0 \cdot 81(11 / 1350) & 44(184 / 419) & 0 \cdot 020 \\ 0 \cdot 70(14 / 1990) & 36(185 / 512) & 0 \cdot 019 \\ 5 \cdot 5(62 / 1120) & 44(92 / 210) & 0 \cdot 13 \\ 4 \cdot 2(46 / 1094) & 31(39 / 127) & 0 \cdot 14 \\ 0 \cdot 38(10 / 2660) & 31(186 / 588) & 0 \cdot 012 \\ 0 \cdot 41(28 / 6770) & 31(186 / 588) & 0 \cdot 013 \\ 7 \cdot 0(70 / 1010) & 36(295 / 727) & 0 \cdot 19 \\ 5 \cdot 0(285 / 5660) & 41(144 / 402) & 0 \cdot 12 \\ 2 \cdot 7(184 / 6910) & 32(149 / 470) & 0 \cdot 080 \\ 3 \cdot 2(109 / 3420) & 41(295 / 727) & 0 \cdot 078 \\ 0 \cdot 77(54 / 7030) & 36(194 / 539) & 0 \cdot 021 \\ 0 \cdot 21(13 / 6190) & 29(161 / 530) & 0 \cdot 0072 \\ 0 \cdot 80(14 / 1750) & 29(224 / 780) & 0 \cdot 028 \\ 0 \cdot 74(10 / 1350) & 29(81 / 282) & 0 \cdot 026 \\ 4 \cdot 3(45 / 1050) & 39(298 / 774) & 0 \cdot 11 \\ 2 \cdot 3(22 / 960) & 24(99 / 411) & 0 \cdot 096 \\ 0 \cdot 28(10 / 3390) & 30(171 / 571) & 0 \cdot 0093\end{array}$




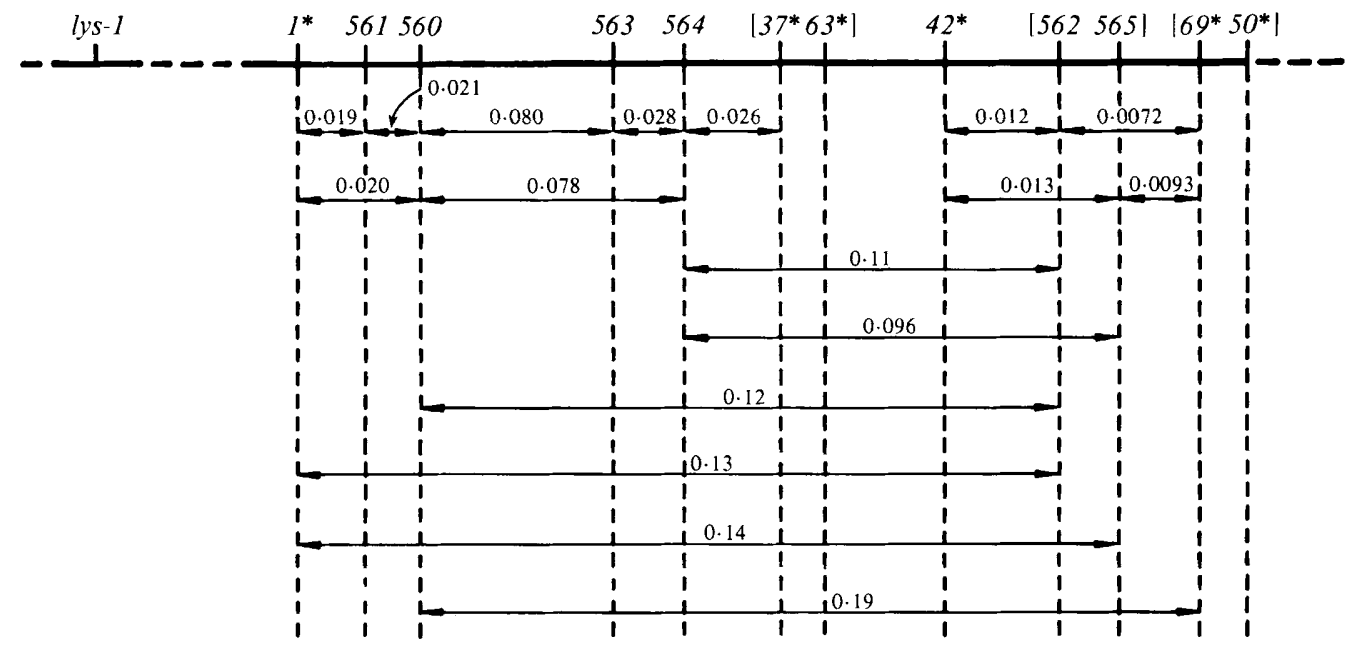

Fig. 2. Map of the spoIIA locus. The vertical lines show the positions of mutations ordered using the data in Table 3. Those mutations previously mapped (Yudkin \& Turley, 1981) are distinguished by asterisks. The map distances shown are the recombination index values from Table 4 . Those mutations which could not be separated by recombination are bracketed.

cistrons in the spoIIA locus. Thus mutations spoIIA42, spoIIA50 and spoIIA69, to the right of the map shown in Fig. 2, were complemented by the plasmid pHM2 carrying a portion of the locus: mutations spoIIA1, spoIIA37 and spoIIA63 were not. Since mutation spo-562 appeared to be located in a different cistron from the other mutations having a $\mathrm{Pho}^{+} \mathrm{Nuc}^{+}$phenotype (see Fig. 6) its position was confirmed in the following experiment. Strains $69.4,562$ and 565 were transformed with purified $\mathrm{pHM} 2 \mathrm{DNA}(1 \mu \mathrm{g})$. Spo ${ }^{+}$transformants were selected and in each case appeared with a frequency of about $10^{5} \mathrm{ml}^{-1}$. In control experiments, spontaneous $\mathrm{Spo}^{+}$ colonies were not detected (frequency $<50 \mathrm{ml}^{-1}$ ). This result indicated that mutations spo-562 and $s p o-565$ both lie within the cloned DNA sequence on pHM2.

\section{Construction of a double mutant}

From the data presented it is clear that mutations conferring $\mathrm{Pho}^{+} \mathrm{Nuc}^{+}$and $\mathrm{Pho}^{-} \mathrm{Nuc}^{-}$ phenotypes may lie in either the complemented or non-complemented parts of the locus (see Table 6). Thus, it appears that mutations that are very closely linked and lie in either of two, or possibly more, cistrons can cause either partial or total loss of the ability to ploduce alkaline phosphatase and DNAase, as well as varying degrees of oligosporogeny.

There are two ways of interpreting these results: firstly that the gene products act sequentially as regulators; secondly that the gene products are subunits of a single regulatory protein. These alternatives might be distinguished by the properties of a double mutant carrying mutations in different spoIIA cistrons both of which confer a $\mathrm{Pho}^{+} \mathrm{Nuc}^{+}$Osp phenotype on single mutants.

A double mutant of this type, carrying the mutations spoIIA561 and spoIIA562 (one at each end of the map shown in Fig. 2), was isolated from a transformation cross using strain 562.1 as recipient and DNA from strain 561 . About $5 \%$ of the $\mathrm{Spo}^{-}$progeny of this cross differed slightly in appearance from the remainder. One of these unusual colonies was isolated (strain 566) and it was shown to be a spoIIA561/spoIIA562 double mutant as follows. DNA from it was used to transform a series of recipients carrying one or other of the parental mutations to $\mathrm{Lys}^{+}$and the progeny were examined for their Spo phenotype (Table 5). No $\mathrm{Spo}^{+}$transformants were obtained in crosses with 561.1 (spoIIA561) or 562.1 (spoIIA562). As a control, strain 564.1 (spoIIA564) was treated similarly and it gave a small number of $\mathrm{Spo}^{+}$transformants $(0 \cdot 32 \%)$. The small proportion of $\mathrm{Spo}^{+}$transformants in this cross was expected since spoIIA564 lies between spoIIA561 and spoIIA562 (Fig. 2). In other control crosses (Table 5), DNA from strain 561 (spoIIA561) gave $\mathrm{Spo}^{+}$transformants with strains 562.1 and 564.1 but not with 561.1 , and DNA from strain 562 (spoIIA562) gave $\mathrm{Spo}^{+}$transformants with strains 561.1 and 564.1 but not with strain 562.1 . 
Table 5. Confirmation of the genotype of strain 566

DNA from strains 561,562 and 566 was used to transform strains 561.3, 562.3 and 564.3 in turn to Lys ${ }^{+}$. The transformants were examined for their Spo phenotype. The numbers of colonies examined are given in parentheses.

Percentage of $\mathrm{Spo}^{+}$colonies obtained using DNA from:

Recipient

561.3 (spoIIA56I)

562.3 (spoIIA562)

564.3 (spoIIA564)

$\begin{array}{ccc}561 \text { (spoIIA561) } & 562(\text { spoIIA562) } & 566 \text { (spoIIA56I spoIIA562) } \\ 0(1650) & 1.9(377) & 0(2180) \\ 3.3(660) & 0(1050) & 0(3280) \\ 1.3(1593) & 4.3(1050) & 0.32(10650)\end{array}$

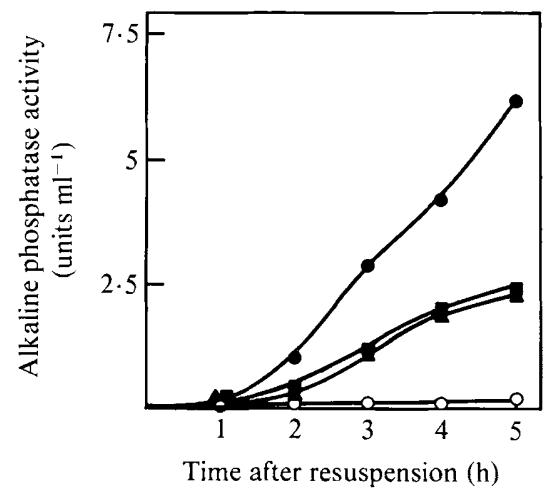

Fig. 3

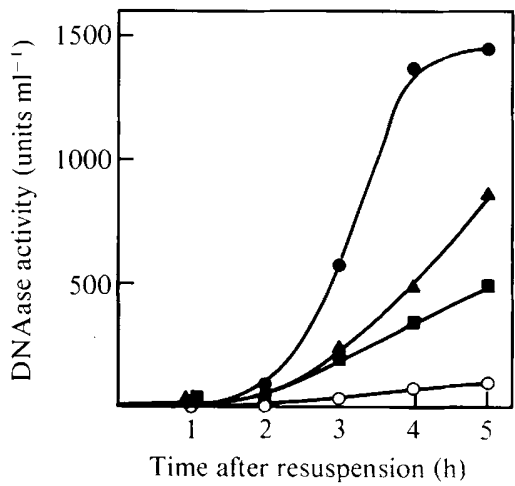

Fig. 4

Fig. 3. Alkaline phosphatase production by spoIIA single and double mutants during sporulation.

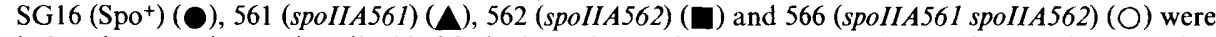
induced to sporulate as described in Methods. At intervals samples were taken and assayed for alkaline phosphatase activity.

Fig. 4. DNAase production by spoIIA single and double mutants during sporulation. SG16 (Spo $\left.{ }^{+}\right)()_{)}$, $561($ spoIIA561) (A), $562($ spoIIA562) (ם) and $566($ spoIIA561 spoIIA562) (O) were induced to sporulate as described in Methods. At intervals samples were taken and assayed for DNAase activity.

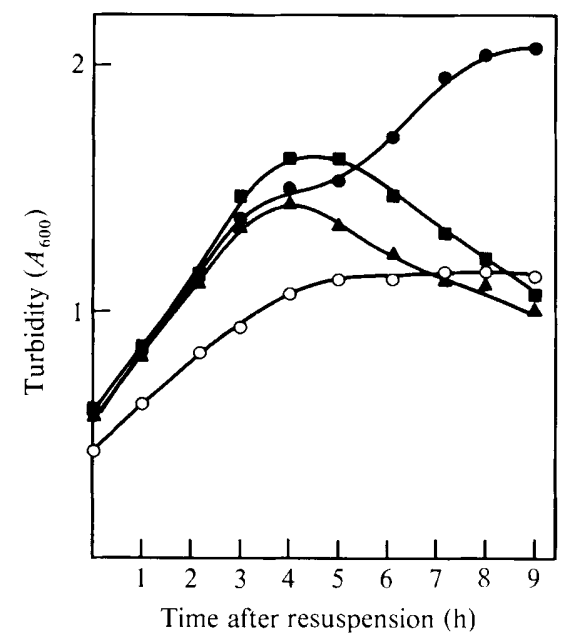

Fig. 5. Growth of spoIIA single and double mutants during sporulation. SG16 (Spo $\left.{ }^{+}\right)(\bigcirc), 561$ $($ spoIIA561) (A), 562 (spoIIA562) ( $\mathbf{\square})$ and 566 (spoIIA561 spoIIA562) (O) were induced to sporulate as described in Methods. At intervals the turbidity $\left(A_{600}\right)$ of each culture was measured. 


\section{Table 6. Genetic and phenotypic properties of spoIIA mutations}

The upper portion of the Table gives the map locations of the mutations in their linear order (see Fig. 2). Below each mutation the phenotypic characteristics are given using data from Table 2 and Results.

\begin{tabular}{|c|c|c|c|c|c|c|c|c|c|c|c|c|}
\hline & \multicolumn{7}{|c|}{ Non-complementable } & \multicolumn{5}{|c|}{ Complementable } \\
\hline & 1 & 561 & 560 & 563 & 564 & 37 & 63 & 42 & 562 & 565 & 69 & 50 \\
\hline Phosphatase & - & + & + & + & + & - & - & - & + & - & - & - \\
\hline DNAase & - & + & + & + & + & - & - & - & + & - & - & - \\
\hline Sporulation & - & Osp & Osp & Osp & Osp & - & - & Osp & Osp & - & - & - \\
\hline Cell stability & + & - & - & - & - & + & + & + & - & + & + & + \\
\hline
\end{tabular}

\section{Phenotypic properties of the double mutant}

In sporulation experiments (Figs 3 and 4) strain 566 showed a typical $\mathrm{Pho}^{-} \mathrm{Nuc}^{-}$phenotype and it had lost the susceptibility to lysis exhibited by both of its parents and by the other $\mathrm{Pho}^{+} \mathrm{Nuc}^{+}$strains (Fig. 5). In addition, this strain was asporogenous $(<50$ heat resistant c.f.u. $\mathrm{ml}^{-1}$ at $t_{9}$ ) unlike its oligosporogenous parents (Table 2). Strain 566 therefore resembled $\mathrm{Pho}^{-} \mathrm{Nuc}^{-} \mathrm{Spo}^{-}$single mutants rather than either of its parents.

\section{DISCUSSION}

For clarity, the genetic and phenotypic properties of the mutants described in this paper have been assembled in a single diagram (Table 6). The portion of the map to the right of mutations spoIIA37 and spoIIA63 represents that portion of the locus complemented by the plasmid pHM2 (Liu et al., 1982).

From our results it is readily apparent that mutations within this right-hand gene can produce either the $\mathrm{Spo}^{-}$or Osp phenotypes. This confirms the earlier observations of Coote $(1972 a, b)$ that oligosporogeny could be considered as the phenotypic consequence of a leaky mutation in a spo gene. More interesting, in the present context, is the fact that mutation spoIIA562 has the phenotype $\mathrm{Pho}^{+} \mathrm{Nuc}^{+}$Osp Stability-, whereas the closely linked mutations spoIIA565 and spoII 442 generate the phenotype $\mathrm{Pho}^{-} \mathrm{Nuc}^{-} \mathrm{Spo}^{-}$Stability ${ }^{+}$.

In the left-hand sector of the locus one again finds that mutations that are very near to one another may produce sharply contrasting phenotypes (cf. mutations spoIIAI and spoIIA56I).

We can now consider one of the possibilities suggested in the Introduction: that the genes for alkaline phosphatase and DNAase lie on operons that are on the main pathway of spore formation. If that were the case, the partial production of the enzyme should be quite closely correlated with the partial production of spores, i.e. with the degree of oligosporogeny. Clearly, however, this is not so. For instance in strain 562, the synthesis of appreciable amounts of phosphatase and DNAase is associated with a low degree of oligosporogeny (about 100 spores $\mathrm{ml}^{-1}$ ). By contrast, in strain 42.1 there is no measurable production of either enzyme but the spore formation is about 1000 -fold greater (Table 2). This comparison alone shows clearly that the genes for the two enzymes are not on operons of the main pathway. If further support for this contention is required it can be found by comparing the phenotypes of strains 560 and 561 . Phosphatase and DNAase are produced to about the same extent by both (the differences in Table 2 are within the limits of day-to-day variation), whereas the incidence of spores differs by a factor of $10^{3}$.

If it is accepted on this basis that the genes for phosphatase and DNAase are not on operons of the main pathway, the next possibility to consider is that the structural genes for these enzymes may lie together on some other operon and that consequently the two proteins are induced coordinately. There is nothing in Table 2 to contradict this assumption, but it is known from the earlier reports of Akrigg \& Mandelstam (1978) that the appearance of phosphatase precedes that of DNAase. Although the intervening period is somewhat variable ( 40 to $60 \mathrm{~min})$, it is seen quite consistently (Figs 3 and 4). The kinetics of appearance of the two enzymes thus indicate that they are synthesized at distinctly separate times and it is reasonable to conclude that their 
structural genes lie in two different operons. Of course the possibility cannot be ruled out that the enzymes are synthesized simultaneously but that the secretion of one of them is delayed for about an hour. However, this seems less likely than the preceding explanation.

We have largely excluded from this discussion, so far, the stability of the cells in sporulation medium. Although it is likely that the lysis of cells in sporulation medium is due to the induction of a lytic enzyme, we have not identified the enzyme and we cannot, therefore, say anything about the kinetics of its appearance. Nevertheless, the data in Table 6 allow us to conclude firstly that closely linked mutations within a single gene can give rise to both negative and positive stability phenotypes and secondly that either phenotype can occur in conjunction with $\mathrm{Spo}^{-}$or Osp. By the same reasoning as before it can be deduced that the gene concerned is not on an operon of the main sporulation pathway, but it could be on either of the operons containing the genes for phosphatase or DNAase. It cannot consequently be assigned to a fourth operon, though this remains possible.

Coming now to the protein products of the spoIIA locus, at least two alternative explanations are possible. If it is assumed that the locus codes for two polypeptides then (a) the polypeptides could act successively, perhaps enzymically, on some substrate that is converted by their action to a functional inducer or derepressor, or (b) the polypeptides could be subunits of a protein functioning as a regulator.

On either assumption a nonsense mutation in either gene should produce the phenotype $\mathrm{Pho}^{-}$ $\mathrm{Nuc}^{-} \mathrm{Spo}^{-}$. In fact, one of the mutations, that in strain 1, was shown by Yudkin \& Turley (1981) to be a nonsense mutation and its phenotype is as predicted. Clearly, this is an indeterminate finding.

In an attempt to obtain a more interpretable result, a double mutant was constructed using two parents, 561 and 562, each carrying a mutation in a different gene of the locus. Both parents were of the low Osp type (about 100 spores $\mathrm{ml}^{-1}$ ) and $\mathrm{Pho}^{+} \mathrm{Nuc}^{+}$. In the double mutant the spore count was reduced to $<50 \mathrm{ml}^{-1}$. This result would be predicted on either hypothesis and is again indeterminate. However, the phenotype was $\mathrm{Pho}^{-} \mathrm{Nuc}^{-}$, neither enzyme having been produced in significant amounts. If the gene products of the cistrons in spoIIA were acting consecutively one would have expected the double mutant to produce reasonable amounts of both enzymes. The fact that it does not supports but does not prove the assumption that the two polypeptides specified by the spoIIA locus are subunits of a single regulatory protein and do not act successively.

In summary, it is clear that the spoIIA locus has a regulatory function, that both its protein products are involved, and that mutations in either can result in contrasting phenotypic effects in at least two, and possibly three, sporulation operons.

This work was supported by the Science and Engineering Research Council.

\section{REFERENCES}

AkrigG, A. (1978). Purification and properties of a manganese-stimulated deoxyribonuclease produced during sporulation of Bacillus subtilis. Biochemical Journal 172, 69-76.

AKRIGG, A. \& Mandelstam, J. (1978). Extracellular manganese-stimulated deoxyribonuclease as a marker event in sporulation of Bacillus subtilis. Biochemical Journal 172, 63-67.

Anagnostopoulos, C. \& Spizizen, J. (1961). Requirements for transformation in Bacillus subtilis. Journal of Bacteriology 81, 741-746.

Coote, J. G. (1972a). Sporulation in Bacillus subtilis. Characterization of oligosporogenous mutants and comparison of their phenotypes with those of asporogenous mutants. Journal of General Microbiology 71, $1-15$.
COOTE, J. G. (1972b). Sporulation in Bacillus subtilis. Genetic analysis of oligosporogenous mutants. Journal of General Microbiology 71, 17-27.

Coote, J. G. \& Mandelstam, J. (1973). The use of constructed double mutants for determining the temporal order of expression of sporulation genes in Bacillus subtilis. Journal of Bacteriology 114, 12541263.

GlenN, A. R. \& Mandelstam, J. (1971). Sporulation in Bacillus subtilis 168. Comparison of alkaline phosphatase from sporulating and vegetative cells. Biochemical Journal 123, 129-138.

Grant, W. D. (1974). Sporulation in Bacillus subtilis 168. Control of synthesis of alkaline phosphatase. Journal of General Microbiology 82, 363-369.

Guerry, P., Le Blanc, D. J. \& Falkow, S. (1973). 
General method for the isolation of plasmid deoxyribonucleic acid. Journal of Bacteriology 116, 1064 1066.

HocH, J. A. (1971). Selection of cells transformed to prototrophy for sporulation markers. Journal of Bacteriology 105, 1200-1201.

Janssen, F. W., Lund, A. J. \& ANDERSON, L. E. (1958). Colorimetric assay for dipicolinic acid in bacterial spores. Science 127, 26-27.

Klein, R. D., Selsing, E. \& Wells, R. D. (1980). A rapid microscale technique for isolation of recombinant plasmid DNA suitable for restriction enzyme analysis. Plasmid 3, 88-91.

LACKs, S. \& Hotchkiss, R. D. (1960). A study of the genetic material determining an enzyme activity in Pneumococcus. Biochimica et biophysica acta 39, 508518.

LiU, H-M., ChaK, K. F. \& Piggot, P. J. (1982). Isolation and characterization of a recombinant plasmid carrying a functional part of the Bacillus subtilis spoIIA locus. Journal of General Microbiology 128 , 2805-2812.

MARMUR, J. (1961). A procedure for the isolation of deoxyribonucleic acid from micro-organisms. Journal of Molecular Biology 3, 208-218.

Piggot, P. J. (1973). Mapping of asporogenous mutations of Bacillus subtilis: a minimum estimate of the number of sporulation operons. Journal of Bacteriology 114, 1241-1253.

Piggot, P. J. \& CoOTE, J. G. (1976). Genetic aspects of bacterial endospore formation. Bacteriological Reviews 40, 908-962

Porter, A. C. G. \& Mandelstam, J. (1982). A mutant of Bacillus subtilis secreting a DNAase inhibitor during sporulation. Journal of General Microbiology 128, 1903-1914.

SADOFF, H. L. (1966). Glucose dehydrogenase-soluble. I. Bacillus cereus. Methods in Enzymology 9, 103107.

SChaEFfer, P., IONESCo, H., Ryter, A. \& Balassa, G. (1965). La sporulation de Bacillus subtilis: étude génétique et physiologique. Colloques internationaux du Centre national de la recherche scientifique 124 , 553-563.

Sterlini, J. M. \& Mandelstam, J. (1969). Commitment to sporulation in Bacillus subtilis and its relationship to development of actinomycin resistance. Biochemical Journal 113, 29-37.

Waites, W. M., Kay, D., Dawes, I. W., Wood, D. A., WarRen, S. C. \& Mandelstam, J. (1970). Sporulation in Bacillus subtilis. Correlation of biochemical events with morphological changes in asporogenous mutants. Biochemical Journal 118, 667-676.

WARD, J. B., JR \& ZAHLER, S. A. (1973). Genetic studies of leucine biosynthesis in Bacillus subtilis. Journal of Bacteriology 116, 719-726.

Young, M. \& Mandelstam, J. (1979). Early events during bacterial endospore formation. Advances in Microbial Physiology 20, 103-162.

YudKIN, M. D. \& TURLEY, L. (1980). Suppression of asporogeny in Bacillus subtilis. Allele-specific suppression of a mutation in the spoIIA locus. Journal of General Microbiology 121, 69-78.

YUdKIN, M. D. \& TURLEY, L. (1981). Mapping of six mutations in the spoIIA locus of Bacillus subtilis and studies of their response to a nonsense suppressor. Journal of General Microbiology 124, 255-261. 